\title{
Synthesis of Janus rubber hybrid particles and interfacial behavior
}

Huarong Nieł, Cao Zhangł, Yuewen Liu, Aihua He*
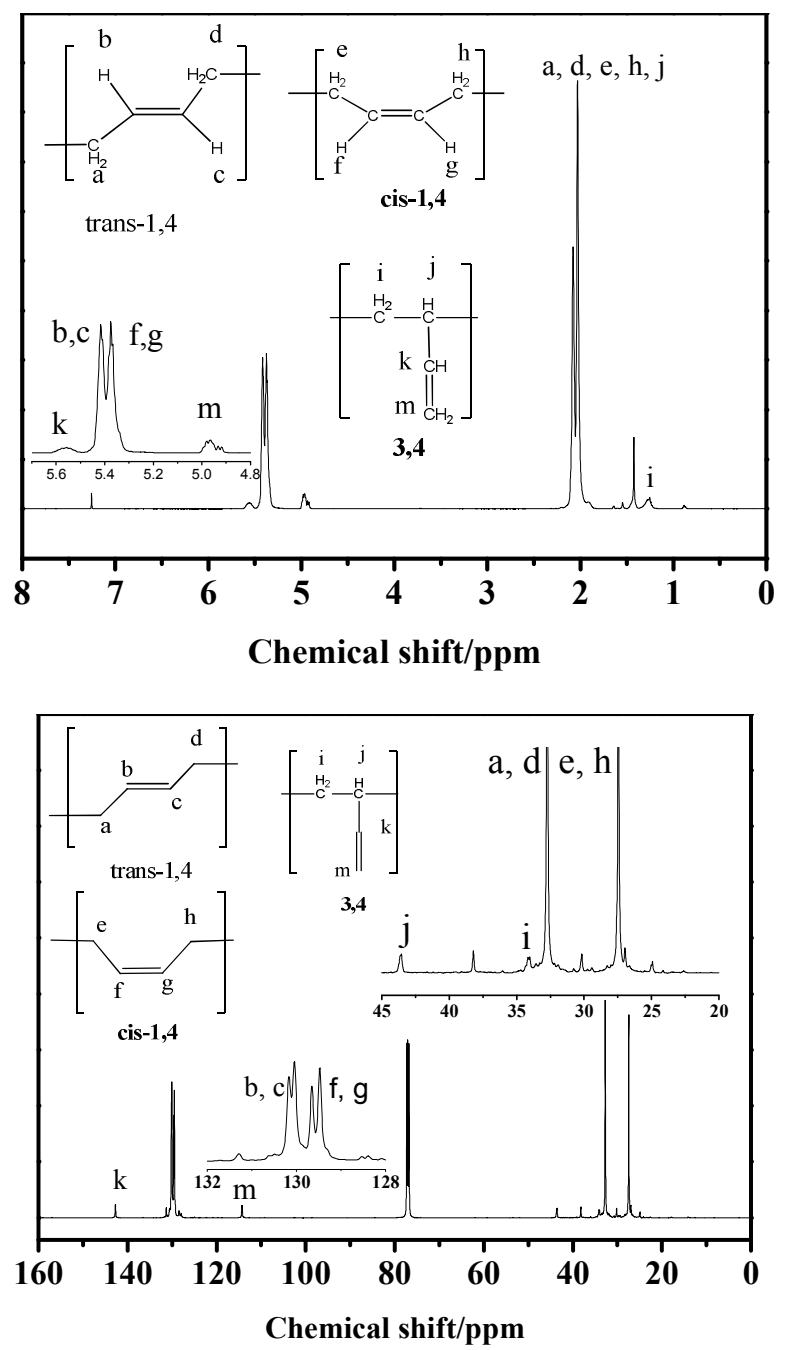

Figure S1. ${ }^{1} \mathrm{H}$ NMR and ${ }^{13} \mathrm{C}$ NMR spectra of alkyne terminated polybutadiene. 


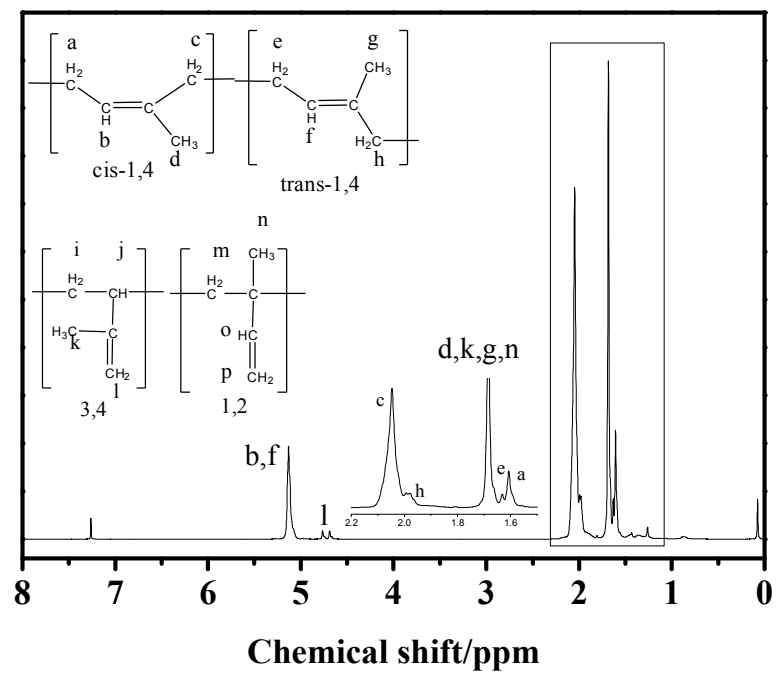

Figure S2. ${ }^{1} \mathrm{H}$ NMR of free polyisoprene.

(a1)

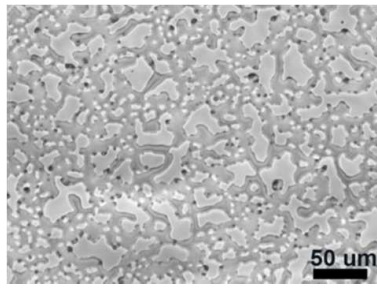

(a2)

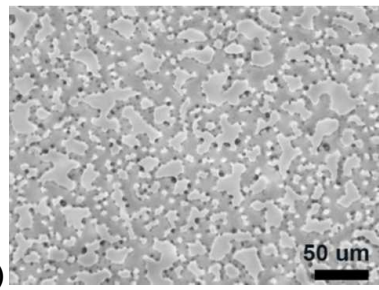

(a3)

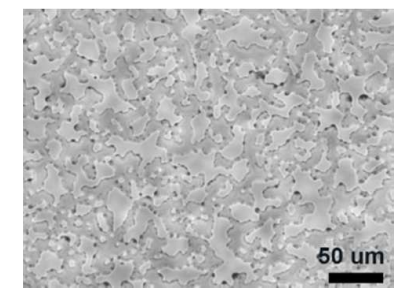

(b3)

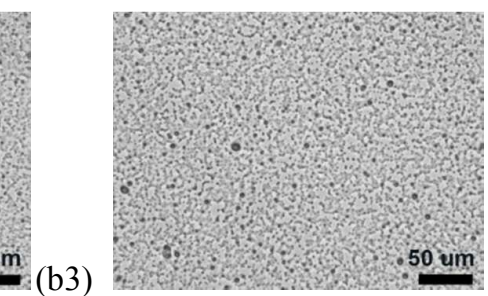

(b1)

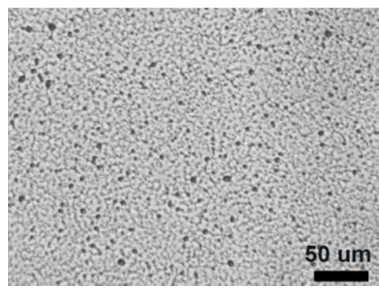

(b2)

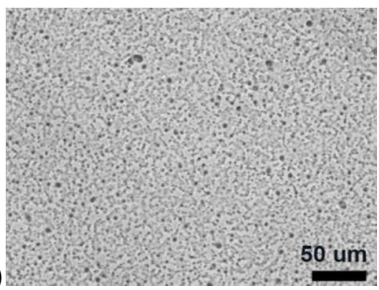

Figure S3. Phase contrast optical microscopic images of the PI/PBd $(6 / 4 \mathrm{wt} / \mathrm{wt})$

blends illustrating phase stability with the varied contents of PI-SiO2@PDVB-PBd (wt $\%$ ) under thermal annealing: (a) $1.85 \mathrm{wt} \%$ of particles; (b) $5.55 \mathrm{wt} \%$ of particles. (1) As spun samples at room temperature, (2) samples annealed at $90{ }^{\circ} \mathrm{C}$ for $1 \mathrm{~h}$, (3) samples annealed at $90{ }^{\circ} \mathrm{C}$ for $10 \mathrm{~h}$. The light gray phase is $\mathrm{PBd}$ domain, and the surrounding dark gray phase represents the PI. The black dots are PI-SiO ${ }_{2} @$ PDVB-PBd particles. 